\title{
$\operatorname{micr} \oplus$ biology $\longmapsto \gg \longmapsto$ $\longmapsto "$ !...Comment ...?"
}

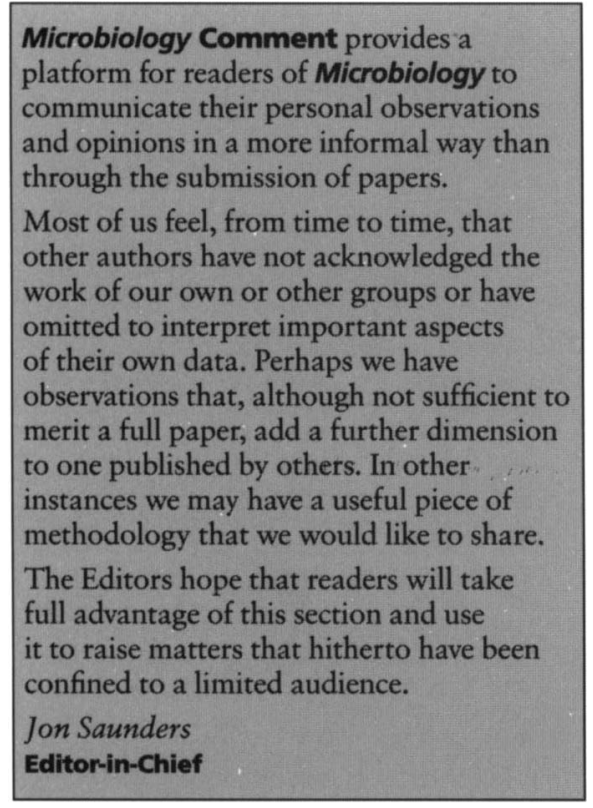

\section{New evidence for old detective work}

In 1982, my laboratory published a paper on the $\operatorname{tam} A$ gene of the ascomycete Aspergillus nidulans (3) following a 1977 report that mutations in $\operatorname{tam} A$ could have a 'repressed' (i.e. resulting in inability to utilize nitrogen sources other than ammonium) or a 'derepressed' (i.e. leading to elevated levels of nitrogen metabolite repressible enzymes and permeases in the presence of ammonium) phenotype (9). In 1973, both such phenotypes had been demonstrated amongst mutations in the are $A$ gene of $A$. nidulans (2), now known to encode a transcriptional activator mediating nitrogen metabolite repression $(7$, $8,10)$. Unfortunately, the $\operatorname{tam} A$ mutations reported in 1977 to have a 'repressed' or 'derepressed' phenotype had been lost a short time later (3). As all such mutations selected in my own laboratory had been are $A$ alleles, we repeated a selection procedure used for the 1977 work. Briefly, our 1982 report concluded that the 'repressed' phenotype was likely to have resulted from the combination of a 'partially repressed' (i.e. conferring resistance to the toxicities of several chemically dissimilar growth inhibitors having the common property that their toxicities can be reversed by exogenously supplied or endogenously synthesized ammonium) $(3,6) \operatorname{tam} A$ mutation and a vitamin B6 auxotrophic pyroB mutation (3). We showed that pyro $B$ mutants can be supplemented by very high concentrations of ammonium (as well as by B6 vitamers) and that 'partially repressed' $\operatorname{tam} A$ mutations reduce the concentration of ammonium required for such supplementation by at least an order of magnitude (3). This gives the superficial appearance of a 'repressed' phenotype, i.e. inability to utilize nitrogen sources other than ammonium (provided, of course, that B6 vitamers are absent). Mutations in $g \ln A$, the structural gene for glutamine synthetase, whether resulting in glutamine auxotrophy or not, physiologically suppress the auxotrophy of pyro $B$ mutations and, even in the presence of a 'partially repressed' $\operatorname{tam} A$ mutation, result in nitrogen metabolite derepression (3). We suggested that the 'derepressed' $\operatorname{tam} A$ 'allele' was likely to have been a combination of the 'partially repressed' $\operatorname{tam} A$ mutation present in the parental strain used for selection of 'derepressed' mutants and a $g \ln A$ mutation too 'leaky' to have a discernible glutamine auxotrophy (3).

Two recent papers support our 1982 proposals. Firstly, a 1995 paper (11), employing ${ }^{15} \mathrm{~N}$ incorporation experiments, reported that ammonium ion is the most efficient source of the nitrogen atom of pyridoxine in another ascomycete, Saccharomyces cerevisiae. This incorporation $(>97 \%)$ argues persuasively for the existence of a step in pyridoxine biosynthesis involving ammonium as substrate. We had proposed that pyro $B$ encodes an enzyme catalysing such a step and that the reaction in question can proceed spontaneously in the presence of high ammonium concentrations (3). As ammonium is a more efficient source of the nitrogen atom of pyridoxine than the amide nitrogen of glutamine (11), the physiological suppression of pyro $B$ mutations by $g \ln A$ lesions (leading to ammonium accumulation) is also explained.

Secondly, a 1996 paper (4) reported that the null $\operatorname{tam} A$ phenotype is that of the well documented $(3,4,6)$ 'partially repressed' type, thus failing to provide any evidence that the 'repressed' and 'derepressed' phenotypes can result solely from $\operatorname{tam} A$ mutations and, by default, supporting our proposal that the 'repressed' and 'derepressed' phenotypes were actually the result of mutations in genes other than $\operatorname{tam} A$. (If $\operatorname{tam} A$ were a positive acting regulatory gene, the null phenotype would be 'repressed', irrespective of whether the $\operatorname{tam} A$ product acts directly or indirectly. If $\operatorname{tam} A$ were negative acting, directly or indirectly, the null phenotype would be 'derepressed'.)

Apart from supporting the detective work in our 1982 paper, does the new work actually reveal anything about the role of $\operatorname{tam} A$ ? Yes, in two respects. Firstly, it is clear from a translational fusion reporter gene experiment that a 'partially repressed' $\operatorname{tam} A$ mutation reduces expression of the acetamidase structural gene amdS (4). Whether such an effect be direct or indirect, however, remains an open question: for example, intracellular pools of ammonium or glutamine involved in nitrogen metabolite repression (3) or pools of endogenously generated acetamidase co-inducers such as $\beta$-alanine (1) or acetyl-CoA (5) might be affected by $\operatorname{tam} A$ mutations. Secondly, the derived $\operatorname{tam} A$ translation product shows some intriguing similarities to that of the UGA35/DAL81/DURL gene of $S$. cerevisiae (required for expression of $\gamma$-aminobutyrateand allophanate-inducible genes) in that each contains a dispensable putative zinc binuclear cluster motif and they share two short regions of striking identity ( 11 out of 12 and 10 out of

\section{- GUIDELINES}

Communications should be in the form of letters and should be brief and to the point. A single small Table or Figure may be included, as may a limited number of references (cited in the text by numbers, and listed in alphabetical order at the end of the letter). A short title (fewer than 50 characters) should be provided.

Approval for publication rests with the Editor-in-Chief, who reserves the right to edit letters and/or to make a brief reply. Other interested persons may also be invited to reply. The Editors of Microbiology do not necessarily agree with the views expressed in Microbiology Comment. Contributions should be addressed to the Editor-in-Chief via the Editorial Office. 
10 identical residues) (4). Regardless of the role of $\operatorname{tam} A$, there is nevertheless no indication on the basis of present evidence that $\operatorname{tam} A$ mutations can have a phenotype other than 'partially repressed'.

\section{Herbert N. Arst, Jr}

Department of Infectious Diseases, Royal Postgraduate Medical School, Du Cane Road, London W12 ONN, UK.

Tel: +44181 3833436. Fax: +44 1813833394 .

1. Arst, H.N., Jr (1976). Integrator gene in Aspergillus nidulans. Nature 262, 231-234.

2. Arst, H.N., Jr \& Cove, D.J. (1973). Nitrogen

metabolite repression in Aspergillus nidulans. Mol Gen Genet 126, 111-141.

3. Arst, H.N., Jr, Brownlee, A.G. \& Cousen, S.A. (1982). Nitrogen metabolite repression in Aspergillus nidulans: a farewell to tamA? Curr Genet 6, 245-257.

4. Davis, M.A., Small, A.J., Kourambas, S. \& Hynes, M.J. (1996). The tamA gene of Aspergillus nidulans contains a putative zinc cluster motif which is not required for gene function. J Bacteriol 178, 3406-3409. 5. Hynes, M.J. (1977). Induction of the acetamidase of Aspergillus nidulans by acetate metabolism. J Bacteriol $131,770-775$.

6. Kinghorn, J.R. \& Pateman, J.A. (1975). Studies of partially repressed mutants at the $\operatorname{tam} A$ and are $A$ loci in Aspergillus nidulans. Mol Gen Genet 140, 137-147. 7. Kudla, B., Caddick, M.X., Langdon, T., MartinezRossi, N.M., Bennett, C.F., Sibley, S., Davies, R.W. \& Arst, H.N., Jr (1990). The regulatory gene areA mediating nitrogen metabolite repression in Aspergillus nidulans. Mutations affecting specificity of gene activation alter a loop residue of a putative zinc finger. EMBO J 9, 1355-1364.

8. Langdon, T., Sheerins, A., Ravagnani, A., Gielkens, M., Caddick, M.X. \& Arst, H.N., Jr (1995). Mutational analysis reveals dispensability of the $\mathrm{N}$-terminal region of the Aspergillus transcription factor mediating nitrogen metabolite repression. Mol Microbiol 17, 877-888. 9. Pateman, J.A. \& Kinghorn, J.R. (1977). Genetic regulation of nitrogen metabolism. In Genetics and
Physiology of Aspergillus, pp. 203-241. Edited by J.E. Smith \& J.A. Pateman. London: Academic Press. 10. Platt, A., Langdon, T., Arst, H.N., Jr, Kirk, D., Tollervey, D., Mates Sanchez, J.M. \& Caddick, M.X. (1996). Nitrogen metabolite signalling involves the $C$ terminus and the GATA domain of the Aspergillus transcription factor AREA and the $3^{\prime}$ untranslated region of its mRNA. EMBO J 15, 2791-2801.

11. Tazuya, K., Adachi, Y., Masuda, K., Yamada, K. \& Kumaoka, H. (1995). Origin of the nitrogen atom of pyridoxine in Saccharomyces cerevisiae. Biochim Biophys Acta 1244, 113-116.

\section{The autoregulatory protein Mor and OxyR are identical}

In 1980, Diderichsen (2) described the existence in many Escherichia coli strains of a phase-variable phenotype that could be distinguished on the basis of colony morphology and the propensity to autoaggregate in broth culture. $\mathrm{He}$ also identified a locus, $f l u$, whose ON-OFF expression appeared to be responsible for the two different phenotypes. Warne et al. (6) later identified an autoregulatory protein, Mor, involved in regulating Flu variation. The mor gene (but not $f(u)$ was cloned, sequenced and mapped to $\sim 89 \mathrm{~min}$ on the $E$. coli chromosome.

We have been interested for a number of years in the presence of phase-variable outer-membrane proteins in E. coli $(1,4,5)$ and the likely identity of one such antigen, termed antigen 43 (Ag43), with the $f u$ gene product. During the course of recent studies, we have shown that the DNA-binding protein OxyR is involved in regulating expression of Ag43. OxyR is a redox-sensitive, LysR-type transcriptional activator known to positively regulate the expression of proteins important under conditions of oxidative stress. However, in the case of Ag43 expression, OxyR acts to repress transcription (3). oxy $R$ also maps at $\sim 89 \mathrm{~min}$ on the $E$. coli chromosome and computer-assisted homology searches have revealed that Mor and OxyR are actually identical, a fact that may be of some interest to other bacterial surface watchers.

Ian Henderson and Peter Owen* Department of Microbiology, Moyne Institute of Preventive Medicine, Trinity College Dublin, Ireland.

*For correspondence. Fax: +35316799294.

1. Caffrey, P. \& Owen, P. (1989). Purification and Nterminal sequence of the $\alpha$ subunit of antigen 43 , a unique protein complex associated with the outer membrane of Escherichia coli. J Bacteriol 171, 3634-3640.

2. Diderichsen, B. (1980). $f u$, a metastable gene controlling surface properties of Escherichia coli. J Bacteriol 141, 858-867.

3. Henderson, I.R., Meehan, M. \& Owen, P. (1997). A novel regulatory mechanism for a novel phase-variable outer membrane protein of Escherichia coli. In Mechanisms in the Pathogenesis of Enteric Diseases, pp. 349-355. Edited by P.S. Paul, D.M. Francis \& D.A. Benfield. New York: Plenum Publishing.

4. Owen, P., Caffrey, P. \& Josefsson, L.G. (1987). Identification and partial characterization of a novel bipartite protein antigen associated with the outer membrane of Escherichia coli. J Bacteriol 169, 3770-3777.

5. Owen, P., Meehan, M., deLoughry-Doherty, H. \& Henderson, I. (1996). Phase-variable outer membrane proteins in Escherichia coli. FEMS Immunol Med Microbiol 16, 63-76.

6. Warne, S.R., Varley, J.M., Boulnois, G.J. \& Norton, M.G. (1990). Identification and characterization of a gene that controls colony morphology and auto-aggregation in Escherichia coli K12. J Gen Microbiol 136, 455-462. 